\title{
Goal aversiveness after escape training with short and long intertrial intervals
}

\author{
HAROLD BABB \\ State University of New York, Binghamton, New York
}

\begin{abstract}
Different intertrial intervals (ITIs) may influence the aversiveness of the goal area in aversive training with one-way procedures. That possibility was explored. Albino rats were given 20 shock-escape runway trials with short or long ITIs followed by 5 extinction test trials with goalbox measures for latency to eat, climb out, and move onto a wood floor. Different measures produced different outcomes. "Time to eat" did not differentiate groups. Massed-trials animals were quicker to "move over" initially but slowed down over trials. Spaced and massed procedures did not produce initial differences on "climb out," but spaced-trials animals speeded up over trials and massedtrials animals slowed down. Results suggested that differences in ITIs did not generate major differences in levels of aversion in the "safe" area. ITI effects on performance may be due to differential effects on the conditioning process.
\end{abstract}

Aversive training in one-way apparatuses versus single compartment and two-way apparatuses pose different problems with respect to the relative aversiveness of the conditioned stimulus (CS) context, and post-unconditioned stimulus (US) conditions. In a one-way apparatus, such as the straight runway, a typical procedure is to apply the CS and US in the context of the startbox and alley, follow this with a period of time in the "safe" goalbox, and then have the animal spend the intertrial interval (ITI) in a retaining cage dissimilar from the runway apparatus. Except for a short period in the startbox at the beginning of each trial, the US is consistently present with the CS, startbox, and alley, whereas the US is consistently absent during the goalbox and ITI confinement periods. In contrast, a typical procedure in a two-way shuttlebox is to present the CS and shock in one compartment, allow escape to an adjoining compartment for a period of time during which the CS and US are absent, and then reinitiate the CS and US in that same compartment, with subsequent escape back to the initial compartment. In this two-way procedure, not only is the "safe" period of confinement the same as the ITI, but the two compartments are alternatingly aversive and safe.

Despite the absence of the US in the goalbox and ITI periods in the one-way procedure, an argument can be made that those periods are not actually devoid of aversive influence. If that is true, the presence of aversiveness in the goalbox could complicate interpretations of self-punitive responding (Babb, Kostyla, \& Bennett, 1980; Brown, 1969; Dean \& Pittman, 1991) but might help to elucidate findings in which small frequencies of goal punishment, with short ITIs, produce facilitated responding and longer frequencies produce suppression (Matthews

Correspondence concerning this article should be addressed to Harold Babb, Department of Psychology, State University of New York at Binghamton, Box 6000, Binghamton, NY 13902-6000.
\& Babb, 1985, 1987). Short ITIs may result in some conditioned aversion to the goalbox since the animal's presence there immediately precedes its reintroduction into the aversive startbox. In addition, fear of the goalbox may occur through generalization from the startbox and alley stimuli, particularly from the grid floor, and more generalization may occur on closely spaced trials since those trials are presumably more similar to each other. Finally, the effects of the US may continue for some length of time after its termination (e.g., Brown \& Cunningham, 1981; Martin, 1969; Melvin, Martin, \& Parsons, 1965). These effects have been referred to variously as "residual emotionality" (Siegel \& Siegel, 1949), "perseverating internal responses" (Melvin et al., 1965), and "post-shock emotionality" (Brown \& Cunningham, 1981). Assuming the US aftereffects constitute a component of the aversive response to shock, rather than an opponent reaction (Solomon \& Corbit, 1974), they may add to any aversive tendencies in the goalbox and they may do so to a greater degree the shorter the interval between trials. Considering these various possible influences, an experiment was designed to test the thesis that the goalbox of a straight runway becomes more aversive when shock-escape trials are massed as compared with spaced, with those terms designating procedures used in prior relevant studies (Babb \& Hom, 1971; Meeker, Babb, \& Matthews, 1980).

After 20 massed or spaced shock-escape trials, animals were given 5 successive trials without shock but with one of three test conditions present in the goalbox. They encountered a small tray of food, a thin, white plywood surface covering the right or left half of the grid floor of the goalbox, or an open top to the goalbox. They were expected eventually to begin eating, move onto the plywood surface, or climb out of the goalbox, and the time that it took to begin those activities on each test trial was recorded. Preliminary testing had indicated that none of those activities was quickly initiated. The rationale for the "time to climb out" measure was based on the "es- 
cape from fear" procedure (McAllister \& McAllister, 1971 ) and the "stimulus directive" proposition that animals withdraw from more aversive to less aversive conditions. With the same rationale, it was assumed that animals would move from the grid floor of the goalbox to a different surface, enabling a "time to move over" measure. The "time to eat" measure was derived from the frequent finding, from conditioned emotional response and other procedures, that fear suppresses eating. The "time to climb out," "time to move over," and "time to eat" measures were taken at the end of a run down the alley, rather than by manual insertion into the goalbox, because the run more closely simulates conditions encountered on an ordinary extinction trial.

\section{METHOD}

\section{Subjects}

The subjects were 36 male albino rats from the laboratory's colony room; they were approximately 105 days of age at the beginning of the experiment. They received water ad lib in their home cage, but access to food was restricted and they were gradually brought to $80 \%$ body weight over a series of $\mathbf{8}$ days and maintained at that weight throughout the experiment.

\section{Apparatus}

The apparatus consisted of a straight runway with an alley $122 \mathrm{~cm}$ long $\times 15.5 \mathrm{~cm}$ wide, a startbox $30 \mathrm{~cm}$ long $\times 15.5 \mathrm{~cm}$ wide, and a goalbox $30 \mathrm{~cm}$ long $\times 26 \mathrm{~cm}$ wide. The runway was $13 \mathrm{~cm}$ high throughout, contained a stainless steel grid floor in the goalbox as well as in the startbox and alley, and was covered with clear acrylic. Guillotine doors, which were also clear acrylic, separated the alley from the startbox and goalbox. The entire apparatus was gray in color except for the grid floor, guillotine doors, and ceiling. Photoelectric beams were situated at the start and end of the alley and $11 \mathrm{~cm}$ inside the goalbox. Scrambled shock of $1 \mathrm{~mA}$ was used, and the CS consisted of an 81- $\mathrm{dB}$ buzzer. The apparatus and stimulus conditions are more thoroughly described elsewhere (Babb et al., 1980).

During acquisition trials, all animals experienced the same apparatus conditions and differed procedurally only with respect to the ITI However, during the Phase 3 test trials, the characteristics of the goalbox were changed so that different animals encountered one of three different conditions. One change was the inclusion of an aluminum tray containing Purina Laboratory Chow. The tray was $2.5 \mathrm{~cm}$ deep, $14 \mathrm{~cm}$ long, and $5 \mathrm{~cm}$ wide. It was placed on the grid floor of the goalbox and was centered lengthwise along the rear wall. The second change was the inclusion of a piece of .4-cm plywood, painted flat white, that was $13 \mathrm{~cm}$ wide and $30 \mathrm{~cm}$ long. It was placed lengthwise on the grid floor of the goalbox, and it covered the right half of the grid for some animals and the left half for others. The third change consisted simply of raising the acrylic lid of the goalbox.

In addition to the runway and associated equipment, a gray plywood box, situated on a rolling cart, was used to carry the animals to and from the experimental room and to hold the animals between trials. The box was partitioned into six individual compartments. Each compartment was fully enclosed except for a hardware-cloth flooring, which admitted adequate air and a small amount of light. The box was situated outside the sound-treated experimental room when trials were in progress.

\section{Procedure}

The experiment consisted of preparatory, acquisition, and testing phases. The preparatory phase consisted of the 8 days during which the animals were brought to $80 \%$ body weight. On the first 3 of those days, each animal was handled for $5 \mathrm{~min}$ in addition to the time taken to weigh it. Acquisition training in the runway was initiated on the day after the end of the preparatory phase. Half of the animals received all 20 acquisition trials and 5 test trials on that day, with about 8-10 sec between trials (massed-trials condition), whereas the remaining animals received their trials at the rate of 5 per day, with approximately $6 \mathrm{~min}$ between trials and approximately $23 \mathrm{~h}$ between each block of 5 trials (spacedtrials condition).

On each acquisition trial, an animal was placed in the startbox for $5 \mathrm{sec}$, and at the end of that time the guillotine door was raised, the buzzer CS came on, and shock was delivered to the startbox and alley. The CS remained on until the animal had interrupted the photoelectric beam in the goalbox, so that on test trials, in particular, the animal would not be able to experience cessation of the CS while still in the alley. Shock ceased as a function of the animal leaving the shock grid in the alley and encountering the nonshock grid in the goalbox. On each trial, the animal was allowed to remain in the goalbox for $30 \mathrm{sec}$ and was then removed. When a massed-trials animal was taken from the goalbox, it was quickly reintroduced into the startbox for the initiation of the next trial. When a spaced-trials animal was removed from the goalbox, it was placed in a compartment of the gray plywood box for the duration of the ITI (within blocks) and then inserted into the startbox for the next trial. After five trials, the spaced-trials animals were returned to the colony room until time for the next day's trials, approximately $23 \mathrm{~h}$ later.

The testing phase began immediately after the last acquisition trial for the massed-trials animals and on the next day for the spaced-trials animals. It consisted of five successive nonshock trials, on each of which the animal was allowed to remain in the goalbox for at least $30 \mathrm{sec}$. After that time, it was removed when it had accomplished a specific task or after 1,000 sec had accumulated. One third (6) of the animals in each of the massed-and spaced-trials groups encountered a tray of food on entering the goalbox. Another third encountered a piece of white plywood covering the right half or the left half of the grid floor. Half (3) of those animals encountered the plywood on the right and half on the left. The remaining third encountered a goalbox situation in which the cover of the goalbox was raised. For each animal, on each test trial, the number of seconds was recorded until it, respectively, picked up a piece of food and began eating it (TE), moved all four feet onto the white plywood surface (MO), or placed all four feet on the top 2-cm edge of the goalbox (CO). Each animal received the same test condition on all five test trials.

\section{RESULTS AND DISCUSSION}

For start times and run times, the median of each successive block of five trials was converted to its reciprocal and multiplied by 100 . The criterion times for the various goalbox test conditions on the five test trials were significantly different $[F(2,30)=13.51, p<.001]$, with latencies longer for time to climb out (CO) than to move onto the plywood floor $(\mathrm{MO})[F(1,30)=11.17, p<$ $.001]$ or to begin eating (TE) $[F(1,30)=26.2, p<.001]$. There was also an interaction between acquisition massing/spacing treatments and test conditions $[F(2,30)=$ $4.09, p<.05]$, with the massed-trials (MT) animals significantly slower to climb out than were the spaced-trials (ST) animals $[F(1,30)=6.33, p<.025]$. Finally, there was an interaction between massing/spacing in acquisition and successive test trials $[F(4,120)=3.44, p<$ $.025]$, with latencies for $\mathrm{CO}, \mathrm{MO}$, and TE decreasing over trials for the ST animals and increasing for the MT animals. However, it is apparent from Figure 1 that this interaction is produced by the $\mathrm{CO}$ and MO measures and not by TE.

Each of the test conditions used was presumed capable of providing an index to the presence of conditioned aversion to the goalbox. Nevertheless, none of the test conditions suggested the presence of substantial aversion to the 


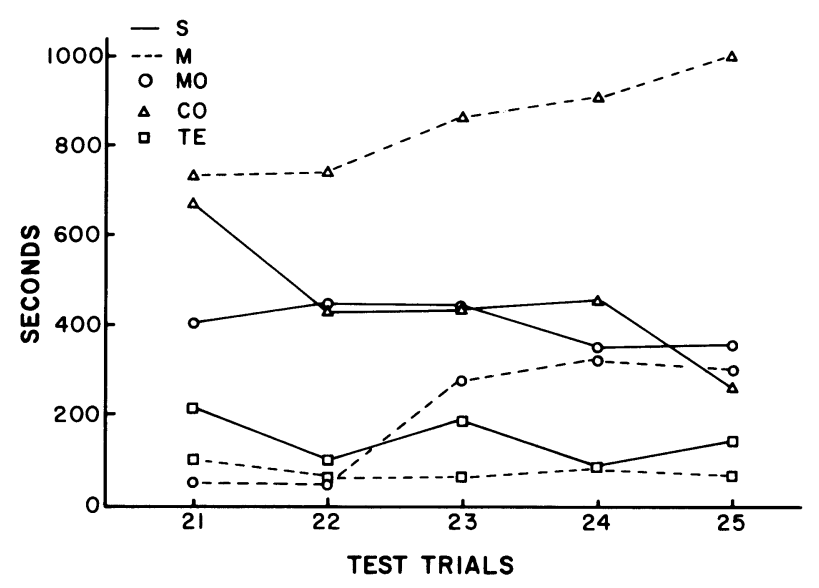

Figure 1. Latency to move over (MO), climb out (CO), and eat (TE) for speced (S) and massed (M) subjects on extinction test trials.

goalbox conditions. The actual mean times for all animals across all five test trials were $658 \mathrm{sec}, 301 \mathrm{sec}$, and $111 \mathrm{sec}$, respectively, for CO, MO, and TE.

Considering each test condition separately, there was no significant difference between massed and spaced groups for TE. For the CO measure, there was again no significant difference between massed and spaced treatments on the initial test trial, with the MT animals averaging $12.15 \mathrm{~min}$ and the ST animals averaging $11.24 \mathrm{~min}$. Over successive test trials, however, the MT animals were decreasingly willing to climb out, and on the fifth test trial all of the animals in that group stayed in the goalbox for the maximum duration allowed (16.67 $\mathrm{min})$. In contrast, the ST animals decreased the time it took them to climb out, and on the fifth test trial they took an average of 6.09 min to do so. Using the Mann-Whitney U test, the difference between the two groups on the last test trial was significant $[U(6,6)=3, p<.05]$. Regarding the MO measure, the MT animals were significantly quicker to move onto the white plywood floor on the first test trial $[U(6,6)=4, p<.05]$, but they slowed down successively over trials and were not significantly different from the ST animals on the last test trial.

In regard to speed measures, acquisition start speeds were not significantly different. Acquisition run speeds, however, produced a significant interaction between massed/ spaced conditions and successive blocks of trials $[F(3,90)$ $=6.73, p<.001]$, indicating faster speeds for the ST animals on the first block $[U(18,18)=61, p<.001]$ but with no significant difference by the last block of trials. The means for run speeds over successive blocks of trials in acquisition were 73, 108, 113, and 116 for the MT animals and $91,117,118$, and 113 for the ST animals. Regarding test trials, start speeds produced a significant interaction between extinction test conditions and successive test trials $[F(8,120)=2.14, p<.05]$ that could be a function of the TE animals starting faster than the MO animals on later trials. For run speeds on test trials, there was an interaction between acquisition massed/spaced conditions and successive test trials $[F(4,120)=4.30, p<.01]$, with the ST animals increasing speeds over trials in comparison with the MT animals.

The TE, MO, and CO measures gave very little indication of differential effects of massing and spacing on the presence of aversion in the goalbox on the first test trial, which was not as subject as later ones to the possible influence of deviations from the 30 -sec acquisition period in the goalbox at the end of each run. Only the MO measure, with a mean of $49 \mathrm{sec}$ for the MT animals and $406 \mathrm{sec}$ for the ST animals on the first test trial, indicated a substantial difference. It would appear that the grid floor of the goalbox retained an aversive influence for the MT animals despite the 30 -sec safe period ending each acquisition trial. For that matter, despite the initial difference in preference, both groups preferred to spend their time on the grid floor. For example, among the 6 animals in the ST group, only 1, on one trial, spent any time on the white floor during the first $30 \mathrm{sec}$ in the goalbox over all five test trials. Interestingly, neither the TE nor CO measure reflected any influence of the initial difference in aversiveness of the grid floor. The only differential aspect of the two measures, with respect to ITI over trials, occurred with the $\mathrm{CO}$ measure, indicating a decrease in latency over trials by the ST animals and an increase by the MT animals. The increase in the climbout latency of the animals given massed trials might suggest a gradual reduction over time in shock aftereffects or the extinction of conditioned aversion or generalized aversion in the goalbox over successive test trials. However, except for the possibility of greater fear of the grid floor by the animals given massed trials, there was no indication that fear of the goalbox was initially greater after trials with short ITIs than after trials with longer ITIs. The general rationale for the possibility of initial differences in fear of the goalbox after escape training does not seem to be supported. If shock aftereffects, for instance, influenced fear within the goalbox, they did not seem to do so differently with respect to short and long ITIs. The very changes used to measure fear in the goalbox, such as the introduction of the tray of food, could have elicited fear responses (Babb, 1963), but they apparently did not do so differentially for massing and spacing procedures.

The successive differences in test trials for the CO measure may have been due to the consequences of being removed from the goalbox on acquisition trials. Since removal of the massed-trials animals from the goalbox consistently resulted in a rapid reintroduction to shock over all acquisition trials, climbing out of the goalbox may not have produced nonaversive safety or reinforcement conditions and might even have been aversive. For the animals given spaced trials in acquisition, removal from the goalbox had consistently resulted in an extended safe period of time in the retaining cage, and even ultimate delivery to the home cage after each fifth daily trial, and did not have the immediate aversive consequence that characterized removal for the massed-trials animals. The safety features of climbing out of the goalbox may have been greater for the spaced-trials animals and more conducive to learning the climb-out response. 
The relevance of the present study to interpretation by theories of classical conditioning is moot, even though several of them attempt to interpret the frequent finding from classical conditioning studies that trials with longer ITIs produce better acquisition performance than do trials with shorter ITIs. Most of the classical conditioning theories are based on types of procedures in which the animal subject is faced with a continuing context or a two-way reversible context (e.g., Gibbon \& Balsam, 1981; Miller \& Schachtman, 1985; Rescorla \& Wagner, 1972), in which ITI effects may be produced by differential extinction of fear to background apparatus cues. That interpretation is not possible with the one-way procedure. Consequently, it appears necessary to look elsewhere than in theories of classical conditioning for an explanation of ITI effects. The results of the present study suggest that ITI differences in performance in the straight runway are not likely to be due to differences in aversiveness accumulating in the goalbox. They are more likely to be a function of the conditioning event producing differences in performance, with some advantage for massed trials in acquisition and a definite advantage for spaced trials in extinction. Specifically, shock aftereffects (postshock emotionality) may accumulate over trials, the more so the smaller the ITI, and produce multidirectional aversion that interferes with conditioning. Although the aftereffects of shock may add to the direct effects of shock on acquisition trials, they may diminish the conditioning of directed response tendencies (Babb et al., 1980), possibly through response competition, and reduce performance when animals are placed on extinction.

\section{REFERENCES}

BABB, H. (1963). Reinforcement and punishment of an escape response. Psychological Reports, 13, 542.

BABB, H., \& Ном, H. L., JR. (1971). Self-punitive responding by goalshocked rats. Journal of Comparative \& Physiological Psychology, 77, 482-488.

BabB, H., Kostyla, S. J., \& BenNett, W. R. (1980). Escape conditioning and goal punishment: Effects of acquisition trials, initial punishment trials and CS extent. Learning \& Motivation, 11, 386-406.
Brown, J. S. (1969). Factors affecting self-punitive locomotor behavior. In B. A. Campbell \& R. M. Church (Eds.), Punishment and aversive behavior (pp. 467-514). New York: Appleton-Century-Crofts.

Brown, J. S., \& Cunningham, C. L. (1981). The paradox of persisting self-punitive behavior. Neuroscience \& Biobehavioral Reviews, 5, 343-354.

Dean, S. J., \& Pittman, C. M. (1991). Self-punitive behavior: A revised analysis. In M. R. Denny (Ed.), Fear, avoidance, and phobias: A fundamental analysis (pp. 259-284). Hillsdale, NJ: Erlbaum.

Gibbon, J., \& BALsAM, P. (1981). Spreading association in time. In C. M. Locuto, H. S. Terrace, \& J. Gibbon (Eds.), Autoshaping and conditioning theory (pp. 219-253). New York: Academic Press.

Martin, R. C. (1969). Self-punitive behavior: One way to stop it. Psychonomic Science, 14, 25-26.

MATtheWs, M. D., \& BABB, H. (1985). Self-punitive behavior: Effects of percentage of shocked acquisition trials and percentage of goal-shocked extinction trials. Psychological Record, 35, 535-547.

MatThews, M. D., \& BABB, H. (1987). Self-punitive behavior: Effects of number of massed acquisition trials and percentage of goalshocked extinction trials. Bulletin of the Psychonomic Society, 25, 475-478.

MCAllister, W. R., \& McAllister, D. E. (1971). Behavioral measurement of conditioned fear. In F. R. Brush (Ed.), Aversive conditioning and learning (pp. 105-179). New York: Academic Press.

Meeker, D. J., BABB, H., \& Matthews, M. D. (1980). Goal vs. alley punishment after escape training: Massed trials and startbox conditions. Bulletin of the Psychonomic Society, 16, 51-54.

Melvin, K. B., Martin, R. C., \& Parsons, G. (1965). Delayed extinction of escape responses: A parametric study. Psychonomic Science, 2, 247-248.

Miller, R. R., \& Schachtman, T. R. (1985). The several roles of the context at the time of retrieval. In P. D. Balsam \& A. Tomie (Eds.), Context and learning (pp. 167-194). Hillsdale, NJ: Erlbaum.

Rescorla, R. A., \& WAGNer, A. R. (1972). A theory of Pavlovian conditioning: Variations in the effectiveness of reinforcement and nonreinforcement. In A. H. Black \& W. F. Prokasy (Eds.), Classical conditioning: II. Current research and theory (pp. 64-99). New York: Appleton-Century-Crofts.

Siegel, P. S., \& Siegel, H. S. (1949). The effect of emotionality on the water intake of the rat. Journal of Comparative \& Physiological Psychology, 42, 12-16.

Solomon, R. L., \& CoRBIT, J. D. (1974). The opponent process theory of motivation: I. Temporal dynamics of affect. Psychological Review, 81, 119-145.

(Manuscript received October 7, 1991.) 